\title{
The effect of death education on fear of death amongst Italian adolescents: A nonrandomized controlled study
}

Ines Testoni, Lucia Ronconi, Illene Noppe Cupit, Elisa Nodari, Guidalberto Bormolini, Annagiulia Ghinassi, Deborah Messeri, Claudia Cordioli \& Adriano Zamperini

To cite this article: Ines Testoni, Lucia Ronconi, Illene Noppe Cupit, Elisa Nodari, Guidalberto Bormolini, Annagiulia Ghinassi, Deborah Messeri, Claudia Cordioli \& Adriano Zamperini (2019): The effect of death education on fear of death amongst Italian adolescents: A nonrandomized controlled study, Death Studies, DOI: 10.1080/07481187.2018.1528056

To link to this article: https://doi.org/10.1080/07481187.2018.1528056

曲 Published online: 18 Jan 2019.

Submit your article to this journal ๘

LIII Article views: 12

View Crossmark data \lceil 


\title{
The effect of death education on fear of death amongst Italian adolescents: A nonrandomized controlled study
}

\author{
Ines Testoni ${ }^{a, b}$, Lucia Ronconi ${ }^{c}$, Illene Noppe Cupit ${ }^{d}$, Elisa Nodarie, Guidalberto Bormolini ${ }^{f}$, \\ Annagiulia Ghinassi ${ }^{9}$, Deborah Messeri ${ }^{9}$, Claudia Cordioli ${ }^{\mathrm{e}}$, and Adriano Zamperini ${ }^{\mathrm{e}}$

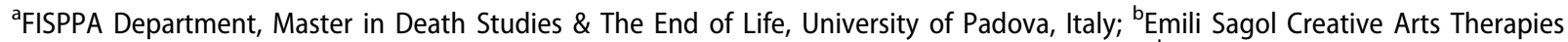

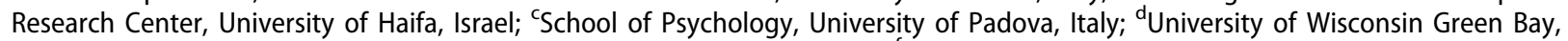 \\ Wisconsin, USA; ${ }^{~}$ FISPPA Department, University of Padova, Padova, Italy; ${ }^{\mathrm{f}}$ Athenaeum Pontificium Sancti Anselmi de Urbe, Vatican; \\ ${ }^{9}$ Tutto é Vita Association, Firenze, Italy
}

\begin{abstract}
This study describes the psychological effects of death education in reducing the fear of death in a large cohort of Italian adolescents. Following the constructs of "distal defenses" and "mortality salience" of Terror Management Theory, this research intervention also evaluated the proposition that spirituality and belief in an afterlife could provide an effective buffer against fear of death. Five hundred thirty-four Italian high school students participated in a school-based death education program with an experimental group and a nonrandomized control condition. Using a pre/post-course design, we assessed fear of death, alexithymia, and representations of death and spirituality for both groups. Results confirmed that the course reduced death fears and the representation of death as annihilation while also enhancing spirituality. In particular, the older participants in the death education course increased their spirituality and decreased their fear of death, whereas females reduced their conviction that death was an absolute annihilation. Finally, the structural model suggested that alexithymia mediates the relationships among fear of death and spirituality; in particular, fear of death predicted more alexithymia and more alexithymia predicted lower spirituality.
\end{abstract}

\section{Terror management theory and death education}

Avoidance of discussion about death is common in contemporary Western societies (Doka, 2007). In the past, religion and the social construction of immortality, along with its rites and artifacts, enabled individuals to face their mortality, but over time these practices were widely dismissed (Kastenbaum, 2004). However, the contemporary tendency toward death denial produces many negative effects. For example, the denial of death can lead to a suppression of death-related thoughts and emotions. In this way, it could go forward as "alexithymia," the tendency toward impoverished emotional experience and language expressing feelings (Bagby, Parker, \& Taylor, 1994). Thus, in order to open up a dialog about death and dying, it may be useful to promote a conscious reflection on existential themes involving concerns about death and beliefs in the afterlife. Death education courses in high schools and universities have been found to be one such vehicle for accomplishing these aims.
As indicated by Wass (2004), the term "death education" refers to a variety of educational activities, intentionally organized by institutions in order to facilitate understandings of death and bereavement. This kind of education was practiced informally throughout human history, but in contemporary Western culture death education courses of a more formal nature have been developed. Parents and educators sometimes express concern that death education courses may trigger death anxiety (Fonseca \& Testoni, 2012) even though these types of worries do not seem to carry over to the daily informal death education frequently experienced through the media. In fact, by resorting to sensationalistic and unrealistic representations, television, journals, and the Internet spread the idea that death is an extraordinary occurrence happening in a mythical space (Gilbert \& Murray, 2007; Noppe, 2007a, 2007b).

According to Terror Management Theory (TMT) (Greenberg, Pyszczynski, \& Solomon, 1986), the denial of death is a psychological defense resulting from the human desire to live in the face of understanding that 
death is inevitable. The paralyzing terror derived from such dissonance is resolved by the removal of mortality thoughts (Arndt, Greenberg, Solomon, Pyszczynski, \& Simon, 1997). The "dual process model" elaborated by TMT researchers suggests that distinct defensive processes are activated by conscious and unconscious fears of death. "Proximal defenses" suppress death-related thoughts by denying one's vulnerability. These defenses are activated when evidence of inevitability of death is brought to current attention, a process known as Mortality Salience (MT). "Distal defenses," consisting of self-esteem and cultural worldviews, intervene to reduce the terror of death whenever death-related information is presented. Self-esteem and faith in one's cultural worldview (e.g., beliefs in the afterlife and social memory) are linked with symbolic systems that provide meaning, values, and beliefs that one is part of something more lasting than oneself (Greenberg, Pyszczynski, Solomon, Simon, \& Breus, 1994; Vess, Routledge, Landau, \& Arndt, 2009).

Religious content has been demonstrated to reduce fear of death in both younger and older adults, whereas belief in an afterlife negatively correlates with fear of death (Cicirelli, 2001; Swanson \& Byrd, 1998; Thorson \& Powell, 2000). Large-scale epidemiological studies have demonstrated that religiousness and spirituality are related to higher levels of health and wellbeing (Park, 2007). Moreover, the faith in the literal (beliefs in the afterlife) or symbolic (social memory) immortality permits people to better manage their coping with fears of death (Heflick \& Goldenberg, 2012; Schmeichel \& Martens, 2005; Solomon, Testoni, \& Bianco, 2017; Wisman \& Heflick, 2016). For example, Dechesne and collaborators (2003) demonstrated that when belief in an afterlife is boosted, the typical effects illustrated by the TMT paradigm are diminished as compared to when belief in the afterlife is discouraged.

Thus, people remain fairly secure as long as they have faith in their worldview and are functioning successfully within that framework. Such worldviews, encompassing spiritual and religious strategies, were the basis of education about death in prior, more traditionally faith-based Western societies. However, in a post-modern and secularized culture, traditional religions have eroded to the point that finding meaning to existential questions about life encounters a number of difficulties, especially for adolescents and young adults who do not experience death education as a substitute for the role previously played by religious teachings (Codato, Shaver, Testoni, \& Ronconi, 2011; Ronconi, Testoni, \& Zamperini, 2009).
Adolescents may be particularly vulnerable to a lack of competent reflections aimed at managing MS (Testoni, Parise, Visintin, Zamperini, \& Ronconi, 2016). As discussed by Erik Erikson $(1968,1987)$, the main psychosocial task of this developmental phase is the loss of a sense of infantile omnipotence. It involves the formation of an awareness of the limits of the life span followed by behaviors reinforcing adolescents' self-esteem. This process, which is fundamentally symbolic, is akin to a dialectical dilemma where life's possibilities contrast with the contemplation of death (Noppe \& Noppe, 1991).

For the adolescent who is oscillating between childhood dependence and adult autonomy, emotional sensitivity to MS may be particularly intense (Bouton, 2003; Noppe, Noppe, \& Bartell, 2006). In addition, adolescents increasingly experience sudden and tragic deaths of their peers, usually from accidents, suicide, and homicide (Cupit \& Kuchta, 2017; Cupit \& Meyer, 2014). The unexpected deaths of young people is a global occurrence-data from U.S. and world health surveys offer a catalog of these untimely deaths, and global conflicts and crises are exacerbating these tragedies (Cupit \& Meyer, 2014). In a death-denying culture (Gorer, 1965), a culturally appropriate adult concept of death (i.e., universality, the cessation of biological activities, irreversibility, understanding causality, noncorporeal continuation) frequently is selftaught (Corr, 1995; Koocher, 1973; Speece, 1995). Often, materialism, fantastic sensationalism, and horror characterize adolescents' exposure to the deathrelated content widely distributed in a variety of media venues. Despite the prevalence of such death encounters for this age group, adolescents frequently are isolated and isolate themselves in facing MS, looking for information and support mostly via social media (Cupit \& Kuchta, 2017; Testoni et al., 2016). One aspect of formal death education that potentially could respond to this need encourages reflection of spiritual and religious issues and experiences that address concerns about one's own mortality (Kastenbaum, 2000; Wass, 2004). This educational process may reduce the negative responses that come from unconscious and uncontrolled defenses against fear of death (Cheng, 2017; Niemiec et al. 2010; Skevington, Gunson, \& O'Connell, 2013).

\section{Objectives of the death education course and aims of the study}

This research started from the conviction that death education should be offered with greater frequency in 
high school curricula, in order to reduce the "conspiracy of silence" that characterizes the censorship of death in contemporary Western culture.

Theory-based assessment of death education (e.g., Currier, Holland, \& Neimeyer, 2008; Kastenbaum, 2004) is notably lacking in the literature. We wanted to reduce this gap by adopting the TMT perspective. The main hypothesis of this study was that students who participated in such a TMT based death education experience would develop a better sense of control over their death representations and the emotions associated with death-anxiety. We wanted to confirm the efficacy of the distal defenses associated with TMT, namely how the representation of immortality could make the death anxiety elicited by the MS more manageable. Our study attempted to demonstrate that: (1) it is possible to have death education experiences without producing negative effects; (2) that the relationships between spirituality/religiosity/representations of death can reduce death anxiety; (3) that the verbal and the artistic elaborations of the fear of death can reduce alexithymia; (4) that a structural model can show how alexithymia mediates the relationships among fear of death, spirituality, representation of death and spirituality

\section{Method}

\section{Participants}

Participants were 534 Italian students in high schools in Northern and Central Italy $(26.6 \%$ boys and $73.4 \%$ girls). Of these, 190 attended the death education course (DE group) and 344 did not have any death education experience (NDE group).

The mean age of DE students was 16.96 years (SD $=1.21$, range $14-20$ years), and the mean age of NDE students was 17.21 years $(\mathrm{SD}=0.69$, range 16-19 years). The DE sample was comprised of 26 (13.7\%) boys and 164 (86.3\%) girls, whereas the NDE sample included 116 (33.7\%) boys and 228 (66.3\%) girls. Twenty-two students (11.6\%) attended a scientific high school, $87(45.8 \%)$ attended a humanities high school and 81 (46.6\%) attended a professional institute. In the NDE group, $124(36.0 \%)$ attended a scientific high school, $74(21.5 \%)$ attended a humanities high school and 146 (42.4\%) attended a professional institute. For the DE group, 132 (69.5\%) indicated a belief in God and 60 (31.6\%) indicated actively practicing their religion. In the NDE group, 238 (69.2\%) indicated a belief in God and 117 (34.0\%) were actively practicing their religion.
The two groups differed in age, $t(532)=-2.64$, $p<.001$, with DE students having a lower mean age than NDE students. Also, gender, $\chi^{2}(1)=25.17$, $p<.001$, and school, $\chi^{2}(2)=50.73, p<.001$, were different in the two groups. Specifically, in DE group there were more females, more humanities high school students and fewer scientific high school students than in NDE group.

\section{Measures}

Testoni Death Representation Scale (TDRS) (Testoni, Ancona, \& Ronconi, 2015). This is a short six-item five-point Likert scale measuring the ontological representations of death either as annihilation (i.e., the end of everything) or as a passage (i.e., belief in an afterlife). Lower scores indicate that the individual represents death as a passage, whereas higher scores represent death as total annihilation. We utilized the Italian version validated by Testoni et al. (2015). These constructs have been used in research examining attachment (Codato et al., 2011), hypnosis (Facco et al., 2017), palliative care (Testoni, Falletti, Visintin, Ronconi, \& Zamperini, 2016; Testoni, Visintin, Capozza, Carlucci, \& Shams, 2016), eating habits (Testoni, Ghellar, Rodelli, De Cataldo, \& Zamperini, 2017), trust and religiosity (Testoni, Bisceglie, Ronconi, Pergher, \& Facco, 2018).

Collett-Lester Fear of Death Scale (Collett \& Lester, 1969; Lester, 2004; Lester \& Abdel-Khalek, 2003). We utilized the revised version (Lester and Abdel-Khalek, 2003), adapted with translation and back translation into the Italian language. This is a frequently used instrument to clearly distinguish between four key dimensions involving death: the state of death vs. the process of dying, and one's own death vs. the death of others. The five-point Likert scale items are included in four subscales: Death of Self, Dying of Self, Death of Others, and Dying of Others. The Collett-Lester has been used to examine a number of factors associated with fear of death, such as age, gender, extraversion, neuroticism, religiosity, general anxiety, and depression. Furthermore, it has been used in evaluating the impact of training programs of death education for nursing students (Mooney, 2005).

World Health Organization Quality Of Life Spirituality, Religiousness, and Personal Beliefs (WHOQOL-SRPB) (Skevington et al., 2013). This is a cross-cultural quality of life assessment tool developed by the WHOQOL Group from 15 international field centers. It is composed of 36 items, expressed as a 
five-point Likert scale, evaluating the influence of religiosity on the quality of life. The scores belong to eight different areas: spiritual connection (CONNECT), meanings and proposals in life (MEANING), astonishment and amazement experiences (AWE), completeness and integration (WHOLE), spiritual strength (STRENGTH), interior peace (PEACE), hope and optimism (HOPE), personal beliefs (SRPB), and faiths (FAITH). It has been used in a wide variety of empirical studies assessing wellbeing and illness (WHOQOL-SRPB Group, 2006). We utilized the Italian version, adapted by Codato and collaborators (2011).

Toronto Alexithymia Scale (TAS) (Bagby et al., 1994). This is a 20-item instrument, expressed in a five-point Likert scale, was developed to measure a general dimension of alexithymia with three inter correlated factors. These three factors reflect distinct facets of the alexithymia construct: difficulty identifying feelings and distinguishing them from the bodily sensations of emotion (e.g., "I am able to describe my feelings easily"), difficulty describing feelings to others (e.g., "I have feelings that I can't quite identify"), and an externally oriented style of thinking (e.g., "I prefer to analyze problems rather than just describe them. TAS has been used to examine emotional understanding by gender, age, culture, mental and physical illness, empathy, deviance, and parental relationships. It is suitable for an adolescent population (Parker, Eastabrook, Keefer, \& Wood, 2010) and has been cross-validated in Italian respondents (Bressi et al., 1996).

\section{Procedure}

The study took place in six Italian high schools in Northern and Central Italy with 4th year of high school students. The "death education project" was presented as a way to encourage discussions on death and spirituality and was aimed at opening dialog about the afterlife. It was approved by the directors of the schools, as well as teachers and parents. In each school, two classes were assigned to the death education group (DE group) and two classes to the no death education group (NDE group). The assignment was not random because we had to involve only the classes with teachers motivated to participate in the project. These motivated teachers were eager to be the facilitators of the DE group.

The activities of death education were divided into "formal" (i.e., lessons in the classroom) and "informal" (i.e., team-based school activities that produced pictures and short movies) categories. The formal death education began with a discussion with students about their personal point of view on death, immortality, and the afterlife. After this open sharing, students were provided with opportunities to reflect on the information and engage in discussions on relevant religious issues in a multicultural perspective. The third step was based on the recognition of the emotions involved in thinking about death, followed by a fourth step which involved a meditation experience. Finally, during the informal stage, students planned out how to represent their emotions via artistic activities. The death education program culminated in an invitation to the students to present their work at a final school exhibition attended by peers, parents, and teachers. All the activities in the classroom totaled between 5 and $10 \mathrm{hr}$ and were led by three psychologists in collaboration with one teacher.

The study followed the APA Ethical Principles of Psychologists and Code of Conduct and the principles of the Declaration of Helsinki and was approved by the Ethics Committee of University of Padova. Participants were informed about the study aims and procedures and assured that participation was voluntary. The confidentiality of their responses was guaranteed. Informed consent was obtained from all participants and their parents.

All participants were tested in the classroom setting on two occasions: immediately before the formal lessons and at the end of the informal activities (about 10 days after the formal lessons) for DE group. The same temporal separation of test administration was used for NDE group.

\section{Statistical analysis}

We conducted our analyses in three steps. First, we evaluated the effect of the death education course by a 2 (time: pre, post) $\times 2$ (group: DE, No DE) ANCOVA with demographic variables that were different in the two groups (age, gender, and school) as covariates for each examined construct. A hierarchical regression analysis on total scores at the second session as dependent variables included demographic variables that differentiated DE and NDE groups and total scores at the first session (step 1). Type of course coded as a dummy variable (step 2) and interactions with course (step 3) was then added to the model. Second, a structural equation model (SEM) was estimated to test both the mediation of TAS total score in the relationship between fear of death and subjects' spiritual attitude and between the death representation 
Table 1. Descriptive statistics, in DE (Death Education) and NDE (No Death Education) groups for each session time, and ANCOVA results for all study variables.

\begin{tabular}{|c|c|c|c|c|c|c|c|c|c|c|c|c|}
\hline \multirow[b]{3}{*}{ Variables } & \multicolumn{4}{|c|}{$\mathrm{DE}$} & \multicolumn{4}{|c|}{ NoDE } & \multicolumn{2}{|c|}{ Ancova Results ${ }^{a}$} & \multirow{2}{*}{\multicolumn{2}{|c|}{$\begin{array}{c}\text { Contrast analysis } \\
\text { Adjusted mean } \\
\text { difference (Post-Pre) }\end{array}$}} \\
\hline & \multicolumn{2}{|c|}{ Pre } & \multicolumn{2}{|c|}{ Post } & \multicolumn{2}{|c|}{ Pre } & \multicolumn{2}{|c|}{ Post } & \multirow[b]{2}{*}{ Time } & \multirow[b]{2}{*}{ Time $x$ Group } & & \\
\hline & M & SD & M & SD & M & SD & M & SD & & & $\mathrm{DE}$ & NoDE \\
\hline \multicolumn{13}{|l|}{ WHOQOL-SRPB Questionnaire } \\
\hline SRPB & 3.42 & 0.76 & 3.38 & 0.79 & 3.41 & 0.79 & 3.33 & 0.80 & $4.08^{*}$ & $<1$ & -0.06 & -0.06 \\
\hline CONNECT & 2.24 & 0.98 & 2.32 & 1.02 & 2.21 & 1.03 & 2.16 & 1.11 & 1.87 & 2.13 & 0.06 & -0.05 \\
\hline MEANING & 3.57 & 0.82 & 3.52 & 0.81 & 3.53 & 0.90 & 3.38 & 0.95 & 1.68 & $<1$ & -0.08 & $-0.13^{* * *}$ \\
\hline AWE & 3.47 & 0.72 & 3.50 & 0.74 & 3.66 & 0.81 & 3.56 & 0.81 & $<1$ & $<1$ & -0.02 & $-0.08^{*}$ \\
\hline WHOLE & 3.12 & 0.63 & 3.18 & 0.61 & 3.23 & 0.67 & 3.11 & 0.71 & $<1$ & $9.35^{* *}$ & 0.05 & $-0.12^{* * *}$ \\
\hline STRENGTH & 2.48 & 1.02 & 2.62 & 0.99 & 2.55 & 1.06 & 2.51 & 1.16 & 1.04 & 2.98 & 0.10 & -0.03 \\
\hline PEACE & 2.79 & 0.82 & 2.95 & 0.81 & 2.88 & 0.87 & 2.95 & 0.90 & 2.04 & $<1$ & $0.13^{*}$ & $0.09^{*}$ \\
\hline HOPE & 2.98 & 0.81 & 3.19 & 0.76 & 3.08 & 0.85 & 2.94 & 0.88 & $<1$ & $27.52^{* * *}$ & $0.20 * * *$ & $-0.12^{* *}$ \\
\hline FAITH & 2.35 & 1.05 & 2.45 & 1.07 & 2.24 & 1.11 & 2.29 & 1.13 & $<1$ & $<1$ & $0.09 *$ & 0.05 \\
\hline Spiritual Quality of Life Total score & 2.94 & 0.60 & 3.01 & 0.61 & 2.98 & 0.62 & 2.92 & 0.69 & 1.82 & $8.84^{* *}$ & $0.05^{*}$ & $-0.05^{*}$ \\
\hline \multicolumn{13}{|l|}{ Toronto Alexithymia Scale } \\
\hline TAS Factor1 & 2.92 & 0.84 & 2.85 & 0.82 & 2.79 & 0.87 & 2.82 & 0.91 & 1.36 & $5.50^{*}$ & $-0.11^{*}$ & 0.04 \\
\hline TAS Factor2 & 3.22 & 0.89 & 3.10 & 0.85 & 3.07 & 0.89 & 3.09 & 0.82 & 2.79 & $10.01 * *$ & $-0.17^{* *}$ & 0.05 \\
\hline TAS Factor3 & 2.40 & 0.60 & 2.46 & 0.59 & 2.34 & 0.58 & 2.49 & 0.62 & $<1$ & 1.45 & 0.07 & $0.14^{* * *}$ \\
\hline TAS Total score & 55.74 & 10.59 & 54.37 & 11.81 & 53.62 & 10.72 & 55.11 & 11.15 & 1.30 & $11.05^{* *}$ & -1.13 & $1.62^{* *}$ \\
\hline \multicolumn{13}{|l|}{ Collett-Lester Fear of Death Scale } \\
\hline Death of Self & 3.15 & 0.84 & 3.03 & 0.82 & 3.18 & 0.89 & 3.09 & 0.88 & 2.98 & $<1$ & $-0.10^{*}$ & $-0.10^{* *}$ \\
\hline Dying of Self & 3.49 & 0.77 & 3.29 & 0.78 & 3.48 & 0.80 & 3.45 & 0.82 & $<1$ & 3.27 & $-0.17^{* *}$ & -0.05 \\
\hline Death of Others & 4.03 & 0.69 & 3.71 & 0.72 & 3.91 & 0.78 & 3.76 & 0.74 & $<1$ & $7.11^{* *}$ & $-0.31 * * *$ & $-0.15^{* * *}$ \\
\hline Dying of Others & 3.77 & 0.77 & 3.53 & 0.75 & 3.75 & 0.73 & 3.65 & 0.69 & 1.05 & 2.14 & $-0.21^{* * *}$ & $-0.11^{* *}$ \\
\hline Fear of Death Total score & 3.61 & 0.61 & 3.39 & 0.64 & 3.58 & 0.67 & 3.49 & 0.65 & $<1$ & $3.97^{*}$ & $-0.20 * * *$ & $-0.10^{* * *}$ \\
\hline \multicolumn{13}{|l|}{ Testoni Death Representation Scale } \\
\hline TDRS Total score & 3.11 & 0.98 & 2.98 & 0.95 & 2.95 & 0.99 & 3.04 & 0.95 & $<1$ & $14.70 * * *$ & $-0.16^{* *}$ & $0.11^{* *}$ \\
\hline
\end{tabular}

scale and subjects' spiritual attitudes. The LISREL Version 8.7 statistical package (Jöreskog \& Sörbom, 2004) was utilized. In this study, the goodness-of-fit was evaluated using multiple criteria: chi-square, goodness-of-fit, Root-Mean-Square-Error of Approximation (RMSEA), Standardized Root Mean Square Residual (SRMR), Non-Normed Fit Index (NNFI), and Comparative Fit Index (CFI); the cutoff point for RMSEA and SRMR values were below .08, and for CFI and NNFI values were above .90 (MacCallum, Browne, \& Sugawara, 1996). Finally, we examined the relationship between fear of death and religiosity.

\section{Results}

\section{The effect of the death education course}

Preliminary ANCOVA shows differences between DE and NDE groups only on two baseline global scores: TDRS Total score, $\mathrm{F}(1,528)=14.29, p<.001$ and TAS Total score, $\mathrm{F}(1,528)=7.54, p=.006$. Students in the DE group have higher scores than students in the NDE group.

The 2 (time: pre, post) $\times 2$ (group: $\mathrm{DE}$, No $\mathrm{DE}$ ) ANCOVA showed a significant time for group interaction for all the constructs' total scores and for several subtotals. It also presented a significant main effect of time only for SRPB subtotal score (see Table 1).

In order to understand the change over time in the two groups, the difference (pre-post) based on adjusted means (adjusted for covariance variables included in the model: age, gender, school) was examined in each group for all study variables (see Table 1). Students who participated in the course of death education improved their Spiritual Quality of Life and reduced their scores on Alexithymia, Fear of Death, and Death Representation as Annihilation. Students of the NDE group, on the contrary, decreased their spiritual quality of life and increased on Alexithymia and Death Representation as Annihilation. NDE subjects also decreased on fear of death.

Hierarchical regression analysis results are presented in Table 2 . All models had high $R$-square values showing a predominant value of the first session total score. ANCOVA results on the importance of the course of death education were confirmed, indicating that participation of the course significantly reduced Fear of Death, Death Representation as, Alexithymia while significantly increasing Spiritual Quality of Life. 
Table 2. Hierarchical regression analysis results for total scores.

\begin{tabular}{|c|c|c|c|c|c|c|c|c|}
\hline \multirow[b]{3}{*}{ Predictors } & \multicolumn{8}{|c|}{ Total scores at the second session } \\
\hline & \multicolumn{2}{|l|}{ SQL } & \multicolumn{2}{|l|}{ TAS } & \multicolumn{2}{|l|}{ FD } & \multicolumn{2}{|l|}{ TDRS } \\
\hline & Delta R-square & Beta & Delta R-square & Beta & Delta R-square & Beta & Delta R-square & Beta \\
\hline $\begin{array}{l}\text { 1. Demographic variables and Total } \\
\text { scores at the first session }\end{array}$ & $.729^{* * *}$ & & $.500^{* * *}$ & & $.526^{* * *}$ & & $.508^{* * *}$ & \\
\hline Age & & $-.05 *$ & & -.00 & & .02 & & .03 \\
\hline Gender $^{\mathrm{a}}$ & & .03 & & -.02 & & $.09^{*}$ & & -.04 \\
\hline School $1^{\text {a }}$ & & -.03 & & $-.09 *$ & & .00 & & -.05 \\
\hline School $2^{\mathrm{a}}$ & & $.05 *$ & & $-.10^{* *}$ & & $-.14^{* * *}$ & & -.06 \\
\hline Spiritual Quality of Life (SQL) Total score & & $.86^{* * *}$ & & $-.15^{* * *}$ & & -.02 & & $-.08^{*}$ \\
\hline TAS Total Score & & .02 & & $.64^{* * *}$ & & -.01 & & $-.07^{*}$ \\
\hline Fear of Death (FD) Total Score & & .02 & & -.06 & & $.68 * * *$ & & -.01 \\
\hline TDRS Total Score & & .02 & & $-.12^{* *}$ & & -.04 & & $.67 * * *$ \\
\hline 2. Course of death education & $.004^{* *}$ & & $.004^{*}$ & & $.005^{*}$ & & $.004 *$ & \\
\hline Course $(0=$ No, $1=$ Yes $)$ & & $.07 * *$ & & $-.07^{*}$ & & $-.07^{*}$ & & $-.07^{*}$ \\
\hline 3. Interactions with course of death education & $.008^{*}$ & & $.017^{*}$ & & .020 & & .013 & \\
\hline Course x Age & & .05 & & .00 & & $-.17^{* *}$ & & .00 \\
\hline Course x Gender & & .06 & & -.12 & & -.11 & & -.06 \\
\hline Course x School1 & & .02 & & -.03 & & -.07 & & .04 \\
\hline Course x School2 & & .08 & & -.01 & & .09 & & -.07 \\
\hline Course $\times$ SQL & & $-.09 * *$ & & $.14^{* *}$ & & -.03 & & .05 \\
\hline Course $x$ TAS & & -.01 & & .04 & & $.08^{*}$ & & -.01 \\
\hline Course $x$ FD & & .00 & & .08 & & -.01 & & $-.08^{*}$ \\
\hline Course $\mathrm{x}$ TDRS & & $-.08 *$ & & $.13 * *$ & & .05 & & -.04 \\
\hline Total R-square & $.740 * * *$ & & $.521 * * *$ & & $.550 * *$ & & $.525^{* * *}$ & \\
\hline $\begin{array}{l}{ }^{\mathrm{a} G e n d e r} \quad(1=\text { Female, } \quad 0=\text { Male }) \text { School } 1 \\
0=\text { Professional Institute). } \\
{ }^{*} p<.05 \text {. } \\
{ }^{* *} p<.01 . \\
{ }^{* * *} p<.001 .\end{array}$ & $(1=$ Scientific & High & chool, $0=$ Pro & ional & Institute; School2 & $(1=\mathrm{Hu}$ & Imanities High & School, \\
\hline
\end{tabular}

The impact, of course, is not conditioned by demographic variables, in fact, only a significant interaction between the demographic variable age and death education course was found for Fear of Death. Specifically, the reduction of fear of death is greater for older students who participated of the course of death education.

The presence of several significant interactions between the constructs under examination at the first session and the death education course instead indicated that the impact of the course depended on the initial value of the constructs. Specifically, highly spiritual students and those who viewed death as annihilation showed less reduction in alexithymia and less increment in quality of spiritual life. In addition, highly alexithymic students showed less reduction of fear of death. Finally, highly fearful students showed more reduction of the representation of death as annihilation.

\section{The mediation of TAS}

Structural equation modeling was used to test the mediation of alexithymia in the relationship between fear of death and spiritual quality of life, and between the death representations and spiritual quality of life for each session time. Fear of Death was a latent variable represented by four observed variables: Death of Self, Dying of Self, Death of Others, and Dying of
Others. Spiritual Quality of Life was a latent variable represented by nine observed variables: SRPB, Spiritual Connection, Meaning \& Purpose in Life, Experiences of Awe and Wonder, Wholeness and Integration, Spiritual Strength, Inner Peace, Hope and Optimism, and Faith. This latent variable refers to subjects' spiritual attitude. High scores indicated that subjects had a high spiritual orientation in life. Alexithymia and Death Representation as Annihilation were assumed as observed variables, so that they were considered represented by TAS Total score and TDRS Total score, respectively.

We started with a full model with all direct and indirect (Alexithymia) effects from Fear of Death and Death Representation as Annihilation to Spiritual Quality of Life; then, we eliminated the non-significant effects. In the final model (Figure 1), all effects were statistically significant at the .05 level in each session. The estimated model showed an adequate fit to the data, as indicated by the following fit indexes for the first session: $\chi^{2}(74$, $N=534)=387.40, \quad p<.001, \quad \mathrm{NNFI}=.92, \quad \mathrm{CFI}=.94$, $\mathrm{RMSEA}=.090, \mathrm{SRMR}=.083$ and the second session: $\chi^{2}(74, \quad N=534)=521.46, \quad p<.001, \quad \mathrm{NNFI}=.91$, $\mathrm{CFI}=.93, \mathrm{RMSEA}=.099, \mathrm{SRMR}=.085$.

The final model confirmed the presence of an indirect effect of Fear of Death on Spiritual Quality of Life; Fear of Death is positively associated with Alexithymia $(\beta=.17$ in both sessions $)$ and 


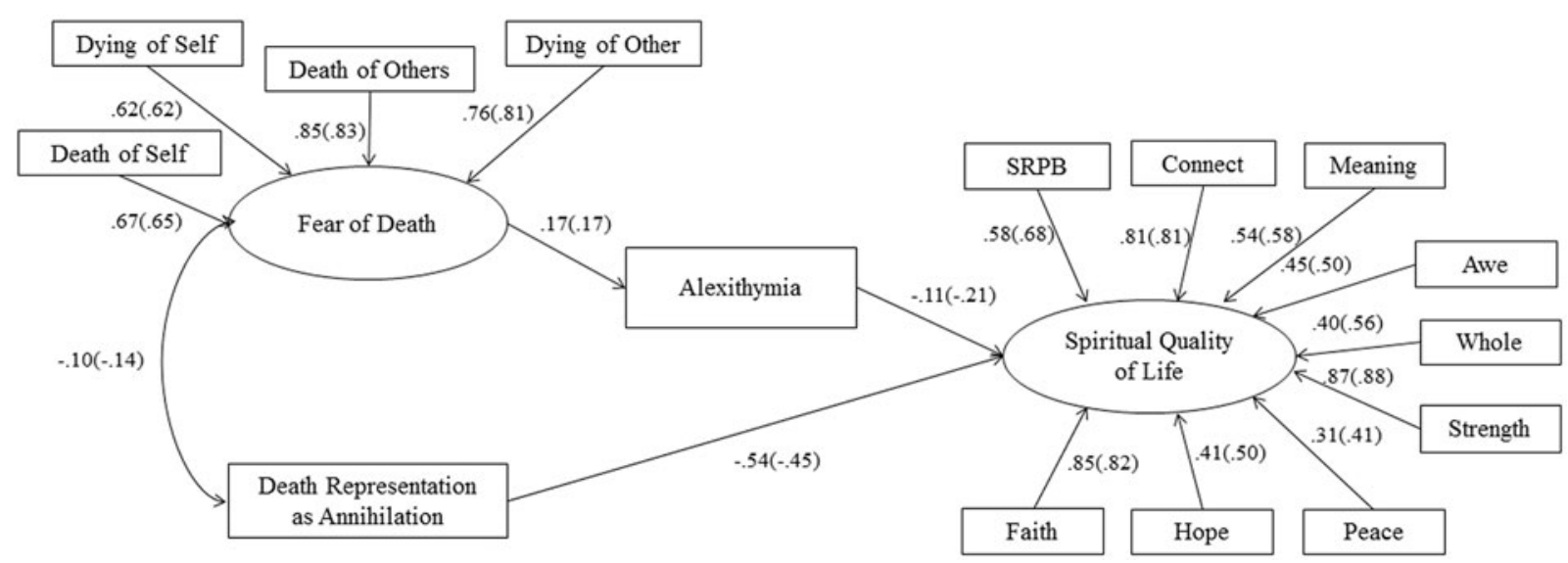

Figure 1. Standardized parameter estimates of the final model. (The numbers in parentheses refer to the coefficients in the second session).

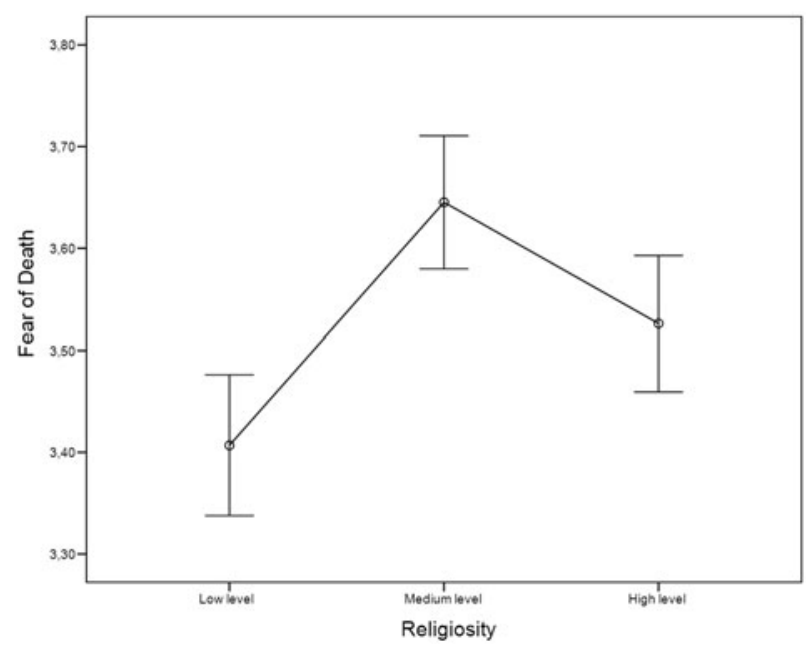

Figure 2. Fear of Death mean scores by Religiosity level.

Alexithymia is negatively associated with Spiritual Quality of Life $(\beta=-.11$ and $\beta=-.21$, in the first and in the second session, respectively). The final model did not confirm the presence of an indirect effect of Death Representation as Annihilation on Spiritual Quality of Life; the relationship between Death Representation as Annihilation and Alexithymia was not statistically significant. There was a negative direct effect of Death Representation as Annihilation to Spiritual Quality of Life $(\beta=-.54$ and $\beta=-.45$, in the first and in the second session respectively).

\section{Fear of death and religiosity}

A factor analysis was conducted on 1068 observations (534 participants for two data collections) to create a single factor of "Religiosity" comprised of the following variables: "Believe in God", "Participate in religious rites," "Death representation as annihilation," and "Spirituality." This factor explained $54 \%$ of the variance and showed a high and positive factor loading for all variables (.73-.78) except for "death representation as annihilation" (-.69). Three levels of religiosity were then created: low (up to 33 percentile), average (from 33 percentile to 66 percentile) and high (greater than 66 percentile). Fear of Death scores were then compared for each level by one-way ANOVA. The effect of religiosity level was significant $\mathrm{F}(2,1065)=12.17, p<.001$ and the mean scores plot showed a non-linear relationship between religiosity and fear of death: fear of death initially increased with religiosity, from low to medium level, but then fear of death decreased with increasing religiosity, from the middle level to high (Figure 2).

\section{Discussion}

The results confirmed that participation in a course of death education reduced death anxiety and the representation of death as annihilation and enhanced a sense of spirituality. Looking at the pre- and postdata from the DE group, findings suggest that for students participating in death education, representing death as annihilation did not significantly decrease their alexithymia. However, the higher their initial fear of death, the more their representation of death as annihilation was reduced. For students who initially scored higher on the dimension of spirituality, participation in the course on death education minimally reduced their level of alexithymia. Moreover, results showed a significant interaction of the course with age. In particular, the reduction of Fear of Death was greater for older participants in the death education course. 
The structural model showed that alexithymia plays the role of mediator only in the relationship between fear of death and spirituality. This suggests that higher fear of death scores is associated with higher levels of alexithymia and higher scores of alexithymia are associated with lower spirituality scores. Moreover, the model indicated that representation of death as annihilation is directly associated with spirituality. Strengthening spirituality in a death education course may reduce alexithymia, death anxiety and fear of annihilation (Testoni, 2016; Testoni et al., 2018).

As confirmed by prior research on death anxiety (Wink \& Scott, 2005), a non-linear relationship between fear of death and level of religiosity was found: fear of death initially increases with religiosity, from low to medium level, but then fear of death decreases with increasing religiosity, from the middle level to high. This result suggests that death anxiety is higher when religious content is superficially considered in adolescents' reflections on death, but can also be reduced by providing opportunities for a deeper examination of these issues (Neimeyer, 1994).

Although the results of this study point to the value of death education in high schools, these findings are limited by the nonrandom design. However, the results of our pretest and posttest analysis confirmed our initial hypothesis that it is possible to control anxiety that may derive from MT by fostering reflection on an afterlife and spirituality. The DE course paid particular attention to spirituality/religiosity in order to improve positive feelings such as hope, strength, and peace. In this way, students were better able to recognize negative emotions as related to death anxiety. Perhaps the main value of the DE course was the provision of a safe space for high school students to reflect and meditate on the mysteries of death. The students came to view death as a passage of life. Such positive effects did not appear in the NDE group, whose members presented a significant worsening of their sense of spirituality as well as their meaningmaking with regard to existential questions of life and death. Furthermore, students who did not participate in the death education course demonstrated more total alexithymia. Without important interventions of an existential and developmental nature, adolescents do not learn how to express their emotions about death nor reflect on them. Particularly, troubling was the finding that contemplation of the afterlife caused an amplification of the representation of death as absolute annihilation (Testoni et al., 2015; Ronconi et al., 2009).
The above findings offer a strong argument for furthering theoretically based death education for adolescents. The high school years present a particularly vulnerable period when risk-taking behaviors seem to be related to skepticism about noncorporeal afterlife continuation (Noppe \& Noppe, 1997). Once the province of family and religious education, exposure to death-related content frequently occurs now through sudden and traumatic experiences in the deaths of friends and family members and in social media (Cupit \& Kuchta, 2017). Quality death education programs for high school students would be advanced by more research that looks at the relationships between fear of death, representation of death, and spirituality. In Italy, where end-of-life issues seldom are formally discussed, the findings of the present study are particularly instructive as to how spirituality may be incorporated into a death education program. In addition, assessing death education both within and outside of the U.S. is useful for mitigating educators' and researchers' theoretical and cultural biases (DeSpelder \& Strickland, 2013).

\section{Acknowledgements}

Fondazione Guido Berlucchi (Brescia, Italy), Dr. Alessandro Paterlini; Associazione PRIAMO (Brescia, Italy), Dr. Diana Lucchini; Associazione TuttoèVita (Firenze, Italy).

\section{References}

Arndt, J., Greenberg, J., Solomon, S., Pyszczynski, T., \& Simon, L. (1997). Suppression, accessibility of deathrelated thoughts, and cultural worldview defense: Exploring the psychodynamics of terror management. Journal of Personality and Social Psychology, 73, 5-18. DOI: doi:10.1037/0022-3514.73.1.5

Bagby, R. M., Parker, J. D. A., \& Taylor, G. J. (1994). The twenty-item Toronto Alexithymia Scale-I. Item selection and cross-validation of the factor structure. Journal of Psychosomatic Research, 38, 23-32. DOI: doi:10.1016/ 0022-3999(94)90005-1

Bouton, B. L. (2003). Schools, children and public tragedy. In M. Lattanzi-Licht \& K. J. Doka (Eds.), Living with grief: Coping with public tragedy (pp. 151-164). Washington: Hospice Foundation of America.

Bressi, C., Taylor, G., Parker, J., Bressi, S., Brambilla, V., Aguglia, E., \& ... Invernizzi, G. (1996). Cross validation of the factor structure of the 20-item Toronto Alexithymia Scale: An Italian multicenter study. Journal of Psychosomatic Research, 41, 551-559. doi:10.1016/ S0022-3999(96)00228-0.

Cheng, F. K. (2017). Buddhist insights into life and death: Overcoming death anxiety. Athens Journal of Social Sciences, 4, 67-88. Retrieved from: https://www.athensjournals.gr/social/2017-4-1-4-Cheng.pdf 
Cicirelli, V. G. (2001). Personal meanings of death in older adults and young adults in relation to their fears of death. Death Studies, 25, 663-683. DOI: doi:10.1080/ 713769896

Codato, M., Shaver, P. R., Testoni, I., \& Ronconi, L. (2011). Civic and moral disengagement, weak personal beliefs and unhappiness: A survey study of the "famiglia lunga" phenomenon in Italy. TPM - Testing, Psychometrics, Methodology in Applied Psychology, 18, 87-97. DOI: doi: 10.4473/TPM20.2.6

Collett, L., \& Lester, D. (1969). The fear of death and dying. The Journal of Psychology, 72, 179-181. DOI: doi:10.1080/ 00223980.1969 .10543496

Cupit, I. N., \& Kuchta, O. (2017). Death version 2016: How children and adolescents are learning and grieving in cyberspace. In R. G. Stevenson \& G. R. Cox (Eds.), Children, adolescents and death: Questions and answers (pp.25-36), New York: Routledge/Taylor \& Francis Group.

Cupit, I. C., \& Meyer, K. J. (2014). Accidents and traumatic loss: The adolescent experience. Helping adolescents cope with loss. Washington: Hospice Foundation of America.

Corr, C. A. (1995). Entering into adolescent understandings of death. In E. A. Grollman (Ed.), Bereaved children and teens: A support guide for parents and professionals (pp. 21-35). Boston: Beacon Press.

Currier, J. M., Holland, J. M., \& Neimeyer, R. A. (2008). Making sense of loss: A content analysis of end-of-life practitioners' therapeutic approaches. Omega - Journal of Death and Dying, 57, 121-141. DOI: doi:10.2190/ OM.57.2.a

Dechesne, M., Pyszczynski, T., Arndt, J., Ransom, S., Sheldon, K. M., Van Knippenberg, A., \& Janssen, J. (2003). Literal and symbolic immortality: The effect of evidence of literal immortality on self-esteem striving in response to mortality salience. Journal of Personality and Social Psychology, 84, 722-737. DOI:doi:10.1037/0022514.84.4.722

DeSpelder, L. A., \& Strickland, A. L. (2013). Culture, socialization and death education. In D. K. Meagher \& D. E. Balk (Eds.), Handbook of thanatology (2nd ed., pp. 323-331). New York: Routledge.

Doka, K. J. (2007). Historical and contemporary perspectives on dying. In D. Balk (Ed.), Handbook of thanatology (pp. 19-25). London: Routledge.

Erikson, E. H. (1968). Identity: Youth, and crisis. New York: Norton.

Erikson, E. H. (1987). Late adolescence. In S. Schlein (Ed.), A way of looking at things (pp. 631-643). New York: Norton. (Original work published 1959).

Facco, E., Testoni, I., Ronconi, L., Casiglia, E., Zanette, G., \& Spiegel, D. (2017). Psychological features of hypnotizability: A first step towards its empirical definition. International Journal of Clinical and Experimental Hypnosis, 65, 98-119. DOI: doi:10.1080/ 00207144.2017.1246881

Fonseca, L. M., \& Testoni, I. (2012). The emergence of thanatology and current practice in death education. Omega - Journal of Death and Dying, 64, 157-169. DOI: doi:10.2190/OM.64.2.d
Gilbert, K. R., \& Murray, C. I. (2007). The family, larger systems and death education. In D. Balk (Ed.), Handbook of thanatology (pp. 345-353). London: Routledge.

Gorer, G. (1965). The pornography of death. In G. Gorer (Ed.), Death, grief, and mourning (pp. 192-199). Garden City: Doubleday.

Greenberg, J., Pyszczynski, T., \& Solomon, S. (1986). The causes and consequences of a need for self-esteem: A terror management theory. In R. F. Baumeister (Ed.), Public self and private self (pp. 189-212). New York: SpringerVerlag.

Greenberg, J., Pyszczynski, T., Solomon, S., Simon, L., \& Breus, M. (1994). Role of consciousness and accessibility of death-related thoughts in mortality salience effects. Journal of Personality and Social Psychology, 67, 627-637. DOI: doi:10.1037/0022-3514.67.4.627

Heflick, N. A., \& Goldenberg, J. L. (2012). No atheists in foxholes: Arguments for (but not against) afterlife belief buffers mortality salience effects for atheists. British Journal of Social Psychology, 51, 385-392. DOI: doi: 10.1111/j.2044-8309.2011.02058.x

Jöreskog, K. G., \& Sörbom, D. (2004). LISREL 8.7 for Windows. Lincolnwood, IL: Scientific Software International.

Kastenbaum, R. (2000). The psychology of death (3rd ed.). New York: Spring Publishing.

Kastenbaum, R. (2004). Death, society, and human experience (8th ed.). Boston: Pearson.

Koocher, G. P. (1973). Childhood, death, and cognitive development. Developmental Psychology, 9, 369-375. DOI: doi: $10.1037 / \mathrm{h} 0034917$

Lester, D. (2004). The factorial structure of the revised Collett-Lester Fear of Death Scale. Death Studies, 28, 795-779. DOI: doi:10.1080/07481180490483472

Lester, D., \& Abdel-Khalek, A. (2003). The Collett-Lester Fear of Death Scale: A correction. Death Studies, 27, 81-85. DOI: doi:10.1080/07481180302873

MacCallum, R. C., Browne, M. W., \& Sugawara, H. M. (1996). Power analysis and determination of sample size for Covariance Structure Modeling. Psychological Methods, 1, 130-149. DOI: doi:10.1037/1082-989X.1.2.130

Mooney, D. C. (2005). Tactical reframing to reduce death anxiety in undergraduate nursing students. American Journal of Hospice and Palliative Medicine, 22, 427-432. DOI: doi:10.1177/104990910502200607

Neimeyer, R. A. (1994). Death anxiety handbook: Research, instrumentation, and application. New York: Taylor \& Francis.

Niemiec, C. P., Browne, K. W., Kashdan, T. B., Cozzolino, P. J., Breen, W. E., Levesque Bristol, C., \& Ryan, R. M. (2010). Being present in the face of existential threat: The role of trait mindfulness in reducing defensive responses to mortality salience. Journal of Personality and Social Psychology, 99(2), 344-365. doi:10.1037/a0019388

Noppe, I. C. (2007a). Historical and contemporary perspectives on death education. In D. Balk (Ed.), Handbook of thanatology (pp. 329-335). London: Routledge.

Noppe, I. C. (2007b). Life Span issues and death education. In D. Balk (Ed.), Handbook of thanatology (pp. 337-343). London: Routledge. 
Noppe, I. C., \& Noppe, L. D. (1997). Evolving meanings of death during early, middle, and later adolescence. Death Studies, 21, 253-275. DOI: doi:10.1080/074811897201967

Noppe, I. C., Noppe, L. D., \& Bartell, D. (2006). Terrorism and resilience: Adolescents' and teachers' responses to September, 11, 2001. Death Studies, 30, 41-60. DOI: doi: 10.1080/07481180500348761

Noppe, L. D., \& Noppe, I. C. (1991). Dialectical themes in adolescent concepts of death. Journal of Adolescent Research, 6, 28-42. DOI: doi:10.1177/074355489161003

Park, C. L. (2007). Religiousness/spirituality and health: A meaning systems perspective. Journal of Behavioral Medicine, 30, 319-328. DOI: doi:10.1007/s10865-0079111-x

Parker, J. D. A., Eastabrook, J. M., Keefer, K. V., \& Wood, L. M. (2010). Can alexithymia be assessed in adolescents? Psychometric properties of the 20-item Toronto Alexithymia Scale in younger, middle, and older adolescents. Psychological Assessment, 22, 798-808. DOI: doi: 10.1037/a0020256

Ronconi, L., Testoni, I., \& Zamperini, A. (2009). Validation of the Italian version of the reasons for living inventory. TPM - Testing, Psychometrics, Methodology in Applied Psychology, 16, 151-159. DOI: doi:10.4473/TPM.16.3.4

Schmeichel, B. J., \& Martens, A. (2005). Self-affirmation and mortality salience: Affirming values reduces worldview defense and death-thought accessibility. Personality and Social Psychology Bulletin, 31, 658-667. DOI: doi: 10.1177/0146167204271567

Skevington, S. M., Gunson, K. S., \& O’connell, K. A. (2013). Introducing the WHOQOL-SRPB BREF: Developing a short-form instrument for assessing spiritual, religious and personal beliefs within quality of life. Quality of Life Research, 22, 1073-1083. DOI: doi:10.1007/s11136-0120237-0

Solomon, S., Testoni, I., \& Bianco, S. (2017). Clash of civilizations? Terror Management Theory and the role of the ontological representations of death in contemporary global crisis. TPM Testing Psychometric Methodology in Applied Psychology, 24, 379-398. DOI: doi:10.4473/ TPM24.3.5

Speece, M. W. (1995). The search for the mature concept of death: Progress on its specification and definition. The Forum, 6, 20-23.

Swanson, J. L., \& Byrd, K. R. (1998). Death anxiety in young adults as a function of religious orientation, guilt, and separation-individuation conflict. Death Studies, 22, 257-268. DOI: doi:10.1080/074811898201588

Testoni, I. (2016). Psicologia del lutto e del morire: Dal lavoro clinico alla death education [The psychology of death and mourning: From clinical work to death education]. Psicoterapia e Scienze Umane, 50, 229-252. doi:doi: 10.3280/PU2016-002004

Testoni, I., Ancona, D., \& Ronconi, L. (2015). The ontological representation of death: A scale to measure the idea of annihilation versus passage. Omega - Journal of Death and Dying, 71, 60-81. DOI: doi:10.1177/ 0030222814568289

Testoni, I., Bisceglie, D., Ronconi, L., Pergher, V., \& Facco, E. (2018). Ambivalent trust and ontological representations of death as latent factors of religiosity. Cogent
Psychology, 5, Article ID 1429349. doi: doi:10.1080/ 23311908.2018.1429349

Testoni, I., Falletti, S., Visintin, E. P., Ronconi, L., \& Zamperini, A. (2016). Il volontariato nelle cure palliative: Religiosità, rappresentazioni esplicite della morte e implicite di Dio tra deumanizzazione e burnout [Volunteering in palliative care: Religiosity, explicit representations of death and implicit representations of God between dehumanization and burnout]. Psicologia Della Salute, 2, 27-42. DOI: doi:10.3280/PDS2016-002002

Testoni, I., Ghellar, T., Rodelli, M., De Cataldo, L., \& Zamperini, A. (2017). Representations of death among Italian vegetarians: An ethnographic research on environment, disgust and transcendence. Europe's Journal of Psychology, 13, 378-395. doi:doi:10.5964/ ejop.v13i3.1301

Testoni, I., Parise, G., Visintin, E. P., Zamperini, A., \& Ronconi, L. (2016). Literary plastination: From body's objectification to the ontological representation of death, differences between sick-literature and tales by amateur writers. TPM - Testing, Psychometrics, Methodology in Applied Psychology, 23, 247-263. DOI: doi:10.4473/ TPM23.2.8

Testoni, I., Ronconi, L., Palazzo, L., Galgani, M., Stizzi, A., \& Kirk, K. (2018). Psychodrama and moviemaking in a death education course to work through a case of suicide among high school students in Italy. Frontiers in Psychology, 9, 441. Open Access, doi:doi:10.3389/ fpsyg.2018.00441

Testoni, I., Visintin, E. P., Capozza, D., Carlucci, M. C., \& Shams, M. (2016). The implicit image of God: God as reality and psychological well-being. Journal for the Scientific Study of Religion, 55, 174-184. doi:doi:10.1111/ jssr.12252

Thorson, J. A., \& Powell, F. C. (2000). Death anxiety in younger and older adults. In A. Tomer (Ed.), Death attitudes and the older adult: Theories, concepts and applications (pp. 123-136). Philadelphia: BrunnerRoutledge.

Vess, M., Routledge, C., Landau, M. J., \& Arndt, J. (2009). The dynamics of death and meaning: The effects of death-relevant cognitions and personal need for structure on perceptions of meaning in life. Journal of Personality and Social Psychology, 97, 728-744. DOI: doi:10.1037/ a0016417

Wass, H. (2004). A perspective on the current state of death education. Death Studies, 28, 289-308. DOI: doi:10.1037/ a0016417

WHOQOL-SRPB Group (2006). A cross-cultural study of spirituality, religion and personal beliefs as components of quality of life. Social Science \& Medicine, 62, 1486-1497. DOI: doi:10.1016/j.socscimed.2005.08.001

Wink, P., \& Scott, J. (2005). Does religiousness buffer against the fear of death and dying in late adulthood? Findings from a longitudinal study. The Journals of Gerontology Series B: Psychological Sciences and Social Sciences, 60, 207-214. DOI: doi:10.1093/geronb/60.4.P207

Wisman, A., \& Heflick, N. A. (2016). Hopelessly mortal: The role of mortality salience, immortality and trait selfesteem in personal hope. Cognition and Emotion, 30, 868-889. DOI: doi:10.1080/02699931.2015.1031643 